\title{
First observations of global and seasonal terrestrial chlorophyll fluorescence from space
}

\author{
J. Joiner ${ }^{1}$, Y. Yoshida ${ }^{2}$, A. P. Vasilkov ${ }^{2}$, Y. Yoshida ${ }^{3}$, L. A. Corp ${ }^{4}$, and E. M. Middleton ${ }^{1}$ \\ ${ }^{1}$ NASA Goddard Space Flight Center, Greenbelt, MD, USA \\ ${ }^{2}$ Science Systems and Applications Inc., 10210 Greenbelt, Rd., Ste 400, Lanham, MD, USA \\ ${ }^{3}$ National Institute for Environmental Studies (NIES), Tsukuba-City, Ibaraki, Japan \\ ${ }^{4}$ Sigma Space Corp., 4600 Forbes Blvd., Lanham, MD, USA
}

Received: 19 October 2010 - Published in Biogeosciences Discuss.: 11 November 2010

Revised: 27 February 2011 - Accepted: 1 March 2011 - Published: 8 March 2011

\begin{abstract}
Remote sensing of terrestrial vegetation fluorescence from space is of interest because it can potentially provide global coverage of the functional status of vegetation. For example, fluorescence observations may provide a means to detect vegetation stress before chlorophyll reductions take place. Although there have been many measurements of fluorescence from ground- and airborne-based instruments, there has been scant information available from satellites. In this work, we use high-spectral resolution data from the Thermal And Near-infrared Sensor for carbon Observation - Fourier Transform Spectrometer (TANSO-FTS) on the Japanese Greenhouse gases Observing SATellite (GOSAT) that is in a sun-synchronous orbit with an equator crossing time near 13:00 LT. We use filling-in of the potassium (K) I solar Fraunhofer line near $770 \mathrm{~nm}$ to derive chlorophyll fluorescence and related parameters such as the fluorescence yield at that wavelength. We map these parameters globally for two months (July and December 2009) and show a full seasonal cycle for several different locations, including two in the Amazonia region. We also compare the derived fluorescence information with that provided by the MODIS Enhanced Vegetation Index (EVI). These comparisons show that for several areas these two indices exhibit different seasonality and/or relative intensity variations, and that changes in fluorescence frequently lead those seen in the EVI for those regions. The derived fluorescence therefore provides information that is related to, but independent of the reflectance.
\end{abstract}

Correspondence to: J. Joiner

(joanna.joiner@nasa.gov)

\section{Introduction}

Vegetation is the functional interface between the Earth's terrestrial biosphere and the atmosphere. Terrestrial ecosystems absorb approximately $120 \mathrm{Gt}$ of carbon annually through the physiological process of photosynthesis. About 50\% of the carbon is released by ecosystem respiration processes within short time periods. The remaining carbon is referred to as Net Primary Production (NPP). Disturbances and long term changes of ecosystems release parts of this carbon within the time frame of centuries. There are currently great uncertainties for the human impact on the magnitude of these processes.

Photosynthesis is the conversion by living organisms of light energy into chemical energy and fixation of atmospheric carbon dioxide into sugars; it is the key process mediating 90\% of carbon and water fluxes in the coupled biosphereatmosphere system. Until now, most of the information that has been acquired by remote sensing of the Earth's surface about vegetation conditions has come from reflected light in the solar domain. There is, however, one additional source of information about vegetation productivity in the optical and near-infrared wavelength range that has not been globally exploited by satellite observations. This source of information is related to the emission of fluorescence from the chlorophyll of assimilating leaves; part of the energy absorbed by chlorophyll cannot be used for carbon fixation and is thus reemitted as fluorescence at longer wavelengths (lower energy) with respect to the absorption.

The fluorescence signal originates from the core complexes of the photosynthetic machinery where energy conversion of absorbed photosynthetically active radiation (APAR) occurs. Because the photosynthetic apparatus is an organized structure, the emission spectrum of fluorescence that originates from it is well known; it occurs as a convolution of

Published by Copernicus Publications on behalf of the European Geosciences Union. 


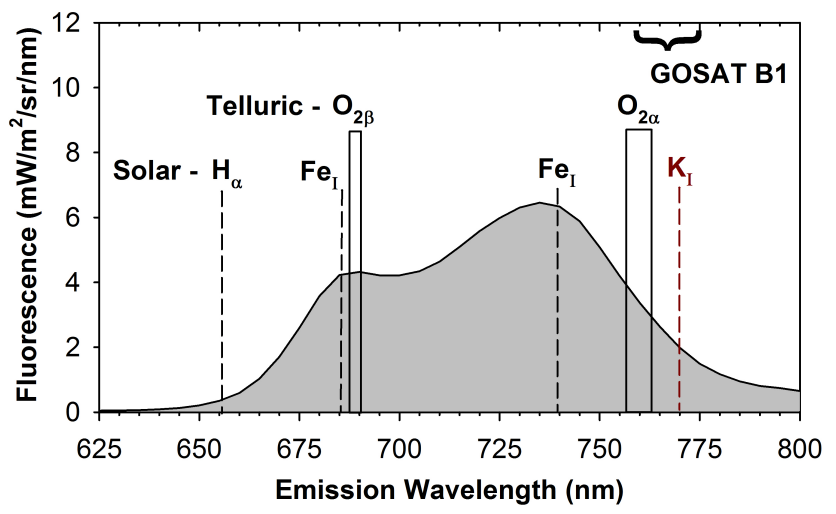

Fig. 1. Simulated solar-induced fluorescence as a function of the emission wavelength with locations of oxygen absorption bands and several solar Fraunhofer lines including the K I line used here.

broad band emission from 650 to $800 \mathrm{~nm}$ with two peaks in the visible and near-Infrared (NIR) at 685 and $740 \mathrm{~nm}$, respectively, as shown in Fig. 1 (e.g., Meroni et al., 2009; Corp et al., 2003, 2006).

The magnitude of the emission is variable and complex. Most studies have shown that in high light conditions (i.e., in the afternoon when many visible satellite measurements are made) and when plants are under stress, fluorescence is correlated with photosynthesis (van der Tol et al., 2009). Variations in fluorescence and photosynthesis in the afternoon occur when protective mechanisms intervene to prevent damage by harmful radicals that are formed under these conditions. Therefore, remotely-sensed chlorophyll fluorescence provides a means to estimate global instantaneous vegetation carbon-related processes that are of major interest for precision farming, forest management, and assessment of the terrestrial carbon budget (e.g., Campbell et al., 2008).

To date, space-based approaches to provide insight into plant physiological status have relied primarily on the measured reflectance that provides information about chlorophyll content. There is observational evidence that chlorophyll fluorescence supplies information content independent of reflectance-based spectral vegetation indices (e.g., Meroni and Colombo, 2006; Guanter et al., 2007; Meroni et al., 2008; Middleton et al., 2008, 2009). A measurement of chlorophyll fluorescence provides an important direct approach for diagnosing vegetation stress, associated with reduced photosynthetic functionality, before chlorophyll reduction occurs. It has therefore been a goal of satellite missions proposed to the European Space Agency (ESA) and the United States National Aeronautics and Space Administration (NASA) (e.g., Davidson et al., 2003).

The measurement of solar-induced chlorophyll fluorescence, $F$, from space is challenging, because its signal (typically $1-5 \%$ in the near-IR) must be differentiated from the much larger reflectance signal. $F$ has been detected from ground- and airborne-based instrumentation by exploiting the fact that $F$ is a proportionally larger fraction of the total radiance within dark lines and bands of the atmospheric spectrum (e.g., Moya et al., 2004; Zarco-Tejada et al., 2009). These dark features include both very narrow solar Fraunhofer lines and wider telluric absorption features such as the $\mathrm{O}_{2}-\mathrm{B}$ band at $687 \mathrm{~nm}$ and the $\mathrm{O}_{2}-\mathrm{A}$ band near $760 \mathrm{~nm}$.

The $\mathrm{O}_{2}$ absorption features, primarily the $\mathrm{O}_{2}$-A band, have been used more extensively with recent ground-, aircraft-, and space-based spectrometers that have spectral resolutions of tenths of a nanometer and larger (individual lines not resolved), because these bands appear wider and deeper and align more closely with the peaks of $F$ (see e.g., the review by Meroni et al., 2009, and more than 40 references within).

In ground-based measurements, typically a separate measurement is made of the incident solar irradiance to account for the atmospheric absorption. Using an aircraft instrument with high spatial resolution, a measurement of a nonfluorescing surface can be used to separate both the emitted and reflected radiation fluxes (e.g., Maier et al., 2002, 2003). Rascher et al. (2009) mapped the relative distribution of fluorescence at $760 \mathrm{~nm}$ using a spectrometer mounted on an aircraft. They used an empirical normalization approach to correct for problems with radiometric calibration. In their approach, observations over bare soil at identical illumination conditions were used as a reference. In air- and space-borne applications, one must additionally account for atmospheric absorption and scattering that takes place between the ground and instrument that further dilutes the $F$ signal (e.g., Guanter et al., 2010; Frankenberg et al., 2011).

The only space-based detection of $F$ to date was achieved by Guanter et al. (2007) with the MEdium Resolution Imaging Spectrometer (MERIS) (Rast et al., 1999) aboard the European Space Agency's (ESA's) ENVIronmental SATellite (ENVISAT). MERIS has two channels near the $\mathrm{O}_{2}$-A band, one near the peak absorption at $760.6 \mathrm{~nm}$ with a $3.75 \mathrm{~nm}$ bandwidth, and one used as a reference band in the nearby continuum at $753.8 \mathrm{~nm}$. MERIS makes measurements at a moderate spatial scale for land studies (better than $300 \mathrm{~m}$ per pixel in its Full Resolution mode).

The MERIS fluorescence retrieval was made for a limited area on one day. A radiative transfer model and other derived properties were used to correct for atmospheric effects and solve for the reflectance $\rho$ and $F$. The derived $F$ was compared with the other MERIS-derived biophysical products.

Here, instead of using $\mathrm{O}_{2}$-A band absorption, we make use of unique high spectral resolution measurements from the Japanese Greenhouse gases Observing SATellite (GOSAT). With GOSAT, we observe filling-in of the potassium (K) I solar Fraunhofer line near $770 \mathrm{~nm}$. Though not designed for this purpose, we demonstrate that fluorescence can be conclusively and directly measured from space and that GOSAT may be used to retrieve $F$ at a regional scale. 
The paper is organized as follows: Sect. 2 describes the GOSAT satellite observations used here. The simulated effect of fluorescence on GOSAT observations and its dependence on surface albedo are shown in Sect. 3 along with other GOSAT simulations. Our approach for the retrieval of the chlorophyll fluorescence signal is given in Sects. 4-5. We show averaged monthly results for July and December 2009 in Sect. 6 and full seasonal cycles (June 2009-May 2010) for several regions. We also compare our fluorescence retrievals with the MODIS normalized and enhanced vegetation indices (NDVI and EVI, respectively). Conclusions are given in Sect. 7.

\section{GOSAT observations}

GOSAT is a satellite mission that was designed to monitor the global distribution of the greenhouse gases $\mathrm{CO}_{2}$ and $\mathrm{CH}_{4}$ (Yokota et al., 2009). It was jointly developed by the Japanese Ministry of the Environment (MOE), the National Institute for Environmental Studies (NIES), and the Japanese Aerospace Exploration Agency (JAXA). GOSAT was launched on 23 January 2009 into a sun-synchronous orbit with a descending node equatorial crossing time near 13:00 LT. Its mean altitude is $666 \mathrm{~km}$, and it has a 3 day repeat cycle.

Here we use spectra from the GOSAT Thermal And Near-infrared Sensor for carbon Observation-Fourier Transform Spectrometer (TANSO-FTS) (Kuze et al., 2009). The TANSO-FTS measures backscattered solar radiation in three shortwave infrared (SWIR) regions, referred to as "bands", centered at $0.76,1.6$, and $2.0 \mu \mathrm{m}$ in two perpendicular polarizations (referred to as $\mathrm{P}$ and $\mathrm{S}$ ). It has a nadir ground footprint of $10.5 \mathrm{~km}$ diameter.

GOSAT also has a Cloud and Aerosol Imager (CAI) with four bands at $0.38,0.67,0.87$, and $1.6 \mu \mathrm{m}$ with footprints between 0.5 and $1.5 \mathrm{~km}$. The CAI was designed to be used for detection and correction of cloud and aerosol effects in the TANSO-FTS spectra.

Chlorophyll fluorescence can be measured within band 1 that extends from approximately 758 to $775 \mathrm{~nm}$ and encompasses the $\mathrm{O}_{2}-\mathrm{A}$ band. The primary function of the $\mathrm{O}_{2}-\mathrm{A}$ band for GOSAT is to account for the effects of cloud and aerosol within the $\mathrm{CO}_{2}$ and $\mathrm{CH}_{4}$ bands. In band 1 , the TANSO FTS has a full-width half maximum (FWHM) of the unapodized Instrument Line-Shape Function (ILSF) between 0.367 and $0.356 \mathrm{~cm}^{-1}$ (or approximately $0.022 \mathrm{~nm}$ ), or a corresponding resolving power $(v / \Delta v)$ of $>35000$. For a typical scene radiance (Lambertian surface albedo of 0.3 at $30^{\circ}$ solar zenith angle), the signal-to-noise ratio (SNR) is approximately 300 .

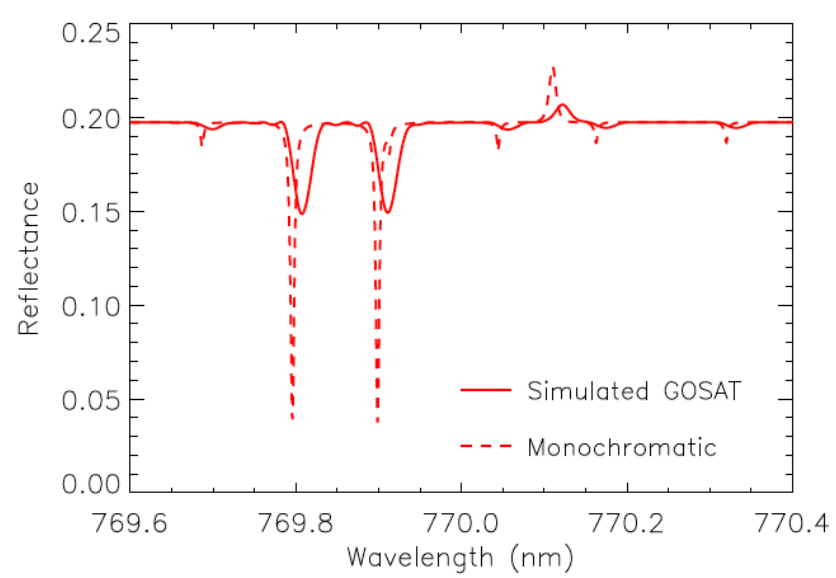

Fig. 2. Simulated monochromatic and GOSAT reflectance spectra assuming a fluorescence of $3 \mathrm{~mW} \mathrm{~m}^{-2} \mathrm{sr}^{-1} \mathrm{~nm}^{-1}, \theta=45^{\circ}$, surface albedo $=0.2$.

\section{GOSAT simulations}

We first simulate the effect of fluorescence on GOSAT topof-atmosphere radiance measurements (combined polarizations) in the vicinity of the $\mathrm{K} I$ line near $770 \mathrm{~nm}$. We use the so-called KPNO2010 high spectral resolution solar irradiance reference spectrum (Chance and Kurucz, 2010), line parameters from the HITRAN 2004 database (Rothman et al., 2005), and a line-by-line code provided by R. Spurr (personal communication, 2010). Because Rayleigh optical thickness is low at these wavelengths, we did not include atmospheric scattering in these simulations. Calculations were performed on a grid with spacing $0.01 \mathrm{~cm}^{-1}$ or $6 \times 10^{-4} \mathrm{~nm}$. The solar spectrum was interpolated onto that grid.

Figure 2 shows simulated monochromatic and GOSAT reflectance spectra computed for a spectrally constant fluorescence of $3 \mathrm{~mW} \mathrm{~m}^{-2} \mathrm{sr}^{-1} \mathrm{~nm}^{-1}$, solar zenith angle of $45^{\circ}$, and a surface albedo of 0.2. The filling-in of the K I line near $770.1 \mathrm{~nm}$ is shown along with several $\mathrm{O}_{2}$ absorption lines including two very weak lines on either side of the $\mathrm{K} I$ filling-in feature.

Figure 3 shows the dependence of the simulated filling-in of both the $\mathrm{K} \mathrm{I}$ line and the $769.9 \mathrm{~nm} \mathrm{O}_{2}$ line on the surface albedo for two values of fluorescence. The $\mathrm{K} \mathrm{I}$ line provides signficantly more filling-in than that of the $\mathrm{O}_{2}$ line. Note that the fluorescence signal within the $\mathrm{O}_{2}$ lines gets absorbed as it travels from the surface to the top-of-atmosphere. This does not happen for the fluorescence filling-in signal within the $\mathrm{K} \mathrm{I}$ line as the atmosphere is relatively transparent at the $\mathrm{K}$ I line wavelengths. The surface albedo affects the observed filling-in, particularly of the $\mathrm{K} I$ line. The $\mathrm{O}_{2}$ line depth depends on the satellite viewing geometry and surface pressure (Guanter et al., 2010). The K I line filling-in does not depend upon these parameters, again because there is no significant terrestrial absorption from $\mathrm{O}_{2}$ within this dark solar line. 


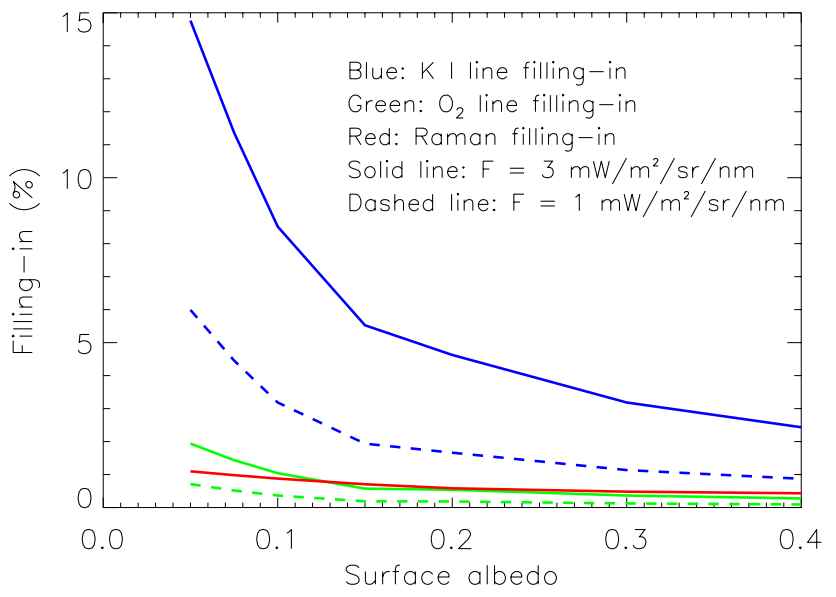

Fig. 3. Simulated GOSAT filling-in of the $\mathrm{O}_{2}$ weak line at $769.9 \mathrm{~nm}$ and the $\mathrm{K} \mathrm{I}$ line as a function of surface albedo. Filling-in of the $\mathrm{K}$ I line due to both fluorescence and rotational-Raman scattering is shown.

We also computed the filling-in of the $\mathrm{K}$ I line due to rotational-Raman scattering (RRS) using the scalar Linearized Discrete Ordinate Radiative Transfer code (LIDORTRRS) of Spurr et al. (2008). Although the amount of atmospheric scattering is relatively small at these wavelengths, the filling-in effect of rotational-Raman scattering is apparent owing to the large depth of the K I line. The spectral signature is very similar to that of line filling due to fluorescence. The amount of filling-in depends upon solar zenith angle, $\theta$, as well as surface albedo. For low to moderate $\theta$ (up to about $50^{\circ}$ ) and typical surface albedos (0.3), this RRS filling-in is about $0.2 \%$ at GOSAT spectral resolution. For lower surface albedo, the filling-in increases (approximately $0.4 \%$ at albedo of 0.1 ). Fig. 3 shows the filling-in at $\theta=70^{\circ}$. For typical surface albedo, the value is close to $0.4 \%$ that corresponds to a filling-in from fluorescence less than about $0.5 \mathrm{~mW} \mathrm{~m}^{-2} \mathrm{sr}^{-1} \mathrm{~nm}^{-1}$.

In our analysis of GOSAT data, we use both Earth and solar spectra. Due to Doppler shifts and other effects, it is necessary to spectrally align Earth and solar spectra. When shifting one spectrum with respect to another, interpolation is required. If spectra are not adequately sampled, as is the case for most space-based instruments, this interpolation will produce errors (Chance et al., 2005). We have simulated this effect based on the approach of Chance et al. (2005) using spline interpolation. Our results indicate that we should expect a significant spectral effect due to undersampling in GOSAT spectra.

Finally, we simulated the effects of $\mathrm{O}_{2}$ absorption on GOSAT observations within the spectral region near the $\mathrm{K}$ I solar line. Here, we computed spectra convolved with the GOSAT ILSF without $\mathrm{O}_{2}$ absorption and with absorption at $20^{\circ}$ and $70^{\circ}$ solar zenith angles. We then examined ratios of these spectra. Our calculations did not show any significant spectral structure due to $\mathrm{O}_{2}$ absorption within the $\mathrm{K}$ I solar line. Spectral structure is shown between stronger $\mathrm{O}_{2}$ lines (away from the solar K I line) when comparing spectra with and without $\mathrm{O}_{2}$ absorption.

\section{Approach}

Figure 4 shows both observed (normalized) solar irradiance and sample Earth-view radiance spectra from the TANSOFTS band 1 and a zoom in at the wavelengths used here for fluorescence retrieval (bottom panel). Resolved lines within the $\mathrm{O}_{2}$-A band are apparent in the Earth spectrum. Solar Fraunhofer lines are seen in both the solar and Earth spectra. Note that there may be small errors in absolute wavelength calibration and that the asymmetric ILSF also produces an apparent wavelength shift between observations and exact positions of solar Fraunhofer lines. There may also be errors in the absolute radiometric calibration as the instrument radiometric sensitivity has decreased by about $10 \%$ from preflight values in band 1 and vicarious calibration is required for correction.

The potassium (K) I line is one of the deepest solar Fraunhofer lines within GOSAT's band $1(\sim 755-775 \mathrm{~nm})$. Although there are several other Fraunhofer lines lying closer to the peak of the $740 \mathrm{~nm}$ fluorescence peak, the K I line was found to be a good starting point for observing chlorophyll fluorescence owing to its great line depth and lack of terrestrial oxygen absorption. The $\mathrm{K}$ I line falls between several weak $\mathrm{O}_{2}$ lines and can be observed in relative isolation with GOSAT's high spectral resolution.

The satellite-observed Earth spectral radiance, $I(\lambda)$, within our spectral region of interest $(769.90-770.25 \mathrm{~nm})$, can be approximated using a Lambertian-equivalent reflectivity ( $R$, assumed constant over our spectral fitting window) surface model and fluorescence, $F$, also here assumed to be spectrally constant, i.e.,

$I(\lambda)=\left(I_{o}(\lambda)+\frac{R T_{d}(\lambda) T_{u}(\lambda)}{1-R S_{b}(\lambda)}\right) \frac{E(\lambda) \cos \theta}{\pi}+\frac{F T_{u}(\lambda)}{1-R S_{b}(\lambda)}$

where $I_{O}$ is the radiance (solar-normalized) due to Rayleigh scattered light in the absence of surface reflectance and fluorescence, $T_{d}$ is irradiance (flux) transmittance (direct + diffuse), $S_{b}$ is the component of the reflected surface radiance that is reflected by the atmosphere back to the surface, $T_{u}$ is atmospheric transmittance of the surface radiance at the top of the atmosphere, and $E(\lambda)$ is the extraterrestrial solar irradiance. This equation holds for monochromatic radiance.

With GOSAT, we have radiance and irradiance measurements (in two polarizations), i.e., monochromatic radiance and irradiance convolved with the $\operatorname{ILSF}, I^{*}(\lambda)$ and $E^{*}(\lambda)$, respectively, where ${ }^{*}$ respresents convolution with the ILSF. We now show the effects of different simplifying assumptions. We first assume that the effects of atmospheric scattering and absorption are negligible on our fitting window (i.e., 

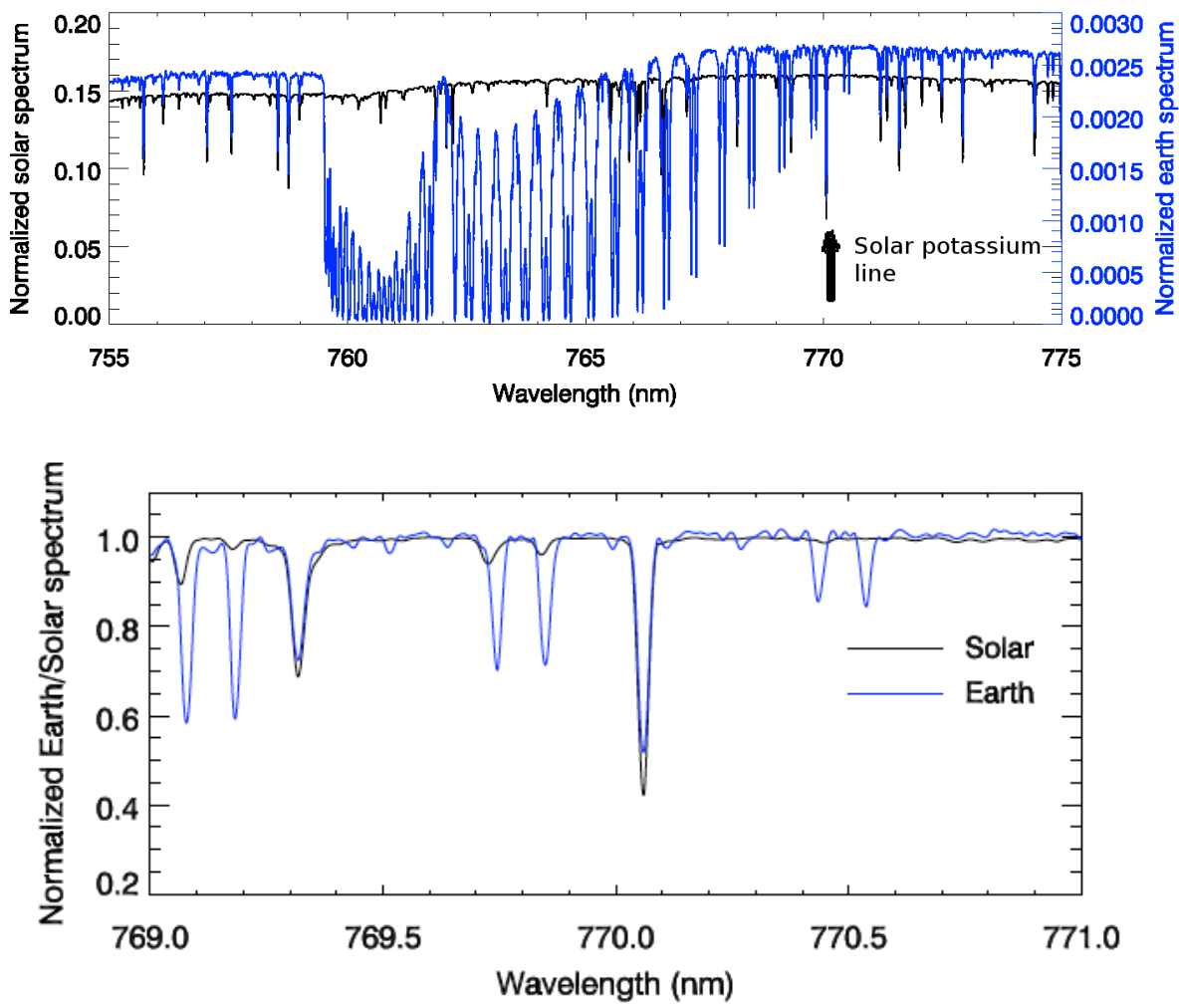

Fig. 4. GOSAT solar and Earth spectra in band $1 \mathrm{P}$ polarization with the K I line (top) and zoom near the wavelengths used in our fitting window (bottom). Spectral data are interpolated using a spline function.

$S_{b}=0, I_{o}=0, T_{u}=1$, and $T_{d}=1$. With these assumptions, the observed total intensity, $I^{*}$, where we now drop the $(\lambda)$, can be simplified to

$$
\begin{aligned}
I^{*} & =\left(\frac{R E \cos \theta}{\pi}+F\right)^{*} \\
& =K E^{*}+F .
\end{aligned}
$$

Similarly, if we assume that atmospheric scattering and absorption is spectrally constant over the wavelengths of interest, then the observed intensity can be rewritten as

$$
\begin{aligned}
I^{*} & =\left(\left[I_{o}+\frac{R T_{d} T_{u}}{1-R S_{b}}\right] \frac{E \cos \theta}{\pi}\right)^{*}+\frac{F T_{u}}{1-R S_{b}} \\
& =K^{\prime} E^{*}+\epsilon F .
\end{aligned}
$$

Equation (3) is similar in form to Eq. (2). Note that the value of $K$ (or $K^{\prime}$ or $R$ ) is of no importance for determining $F$. Similarly, a constant calibration offset in the solar irradiance will not affect the derived fluorescence as the error will be absorbed in the retrieved value of $K$ (or $K^{\prime}$ ). Neglect of scattering and absorption will produce a slight scaling error, $\epsilon$, in $F$ (for $R=0.3$, the error is approximately $0.6 \%$ ).

Since we observe both $I^{*}$ and $E^{*}$, there is no explict use of the ILSF when deriving $F$ using Eq. (3). Therefore, our approach will not suffer from an imperfect model of the ILSF. Furthermore, if $\epsilon \simeq 1$, then radiative transfer calculations are not necessary to derive $F$.
The use of the K I line therefore substantially simplifies a retrieval of $F$ as compared with the $\mathrm{O}_{2}$-A band. The fluorescence signal is not diminished by atmospheric absorption as it is in the $\mathrm{O}_{2}$-A band. With GOSAT's spectral resolution, SNR, and large footprint that ensures capture of substantial photon emissions, our calculations, and those conducted independently by Frankenberg et al. (2011), indicate that detection of ecosystem-scale chlorophyll fluorescence can be achieved.

We use a standard weighted least squares (minimum variance) fitting to estimate the state vector, $\boldsymbol{x}$ consisting of $K$ (or $K^{\prime}$ ), $F$, and the wavelength shift between solar and Earth spectra, i.e.,

$\boldsymbol{x}=\left(\mathbf{H}^{T} \mathbf{S}_{\mathbf{o}}{ }^{-1} \mathbf{H}\right)^{-1} \mathbf{H}^{T} \mathbf{S}_{\mathbf{o}}{ }^{-1}\left(\boldsymbol{y}_{\text {obs }}-\boldsymbol{y}_{\text {calc }}\right)$,

where $\mathbf{H}$ is the Jacobian matrix, $\mathbf{S}_{\mathbf{0}}$ is the observation error covariance, and $\boldsymbol{y}_{\mathbf{o b s}}$ and $\boldsymbol{y}_{\text {calc }}$ are observed and calculated radiances within our fitting window. We use a diagonal observation (in radiance units) error covariance matrix (i.e., this assumes that observational errors are Gaussian with zero bias and uncorrelated with each other). There are two weak $\mathrm{O}_{2}$ lines located within the window, as shown in Figs. 2 and 4. We effectively remove wavelengths affected by these lines by assigning large errors or no weight to them. All other wavelengths are weighted equally such that the retrieval does not 

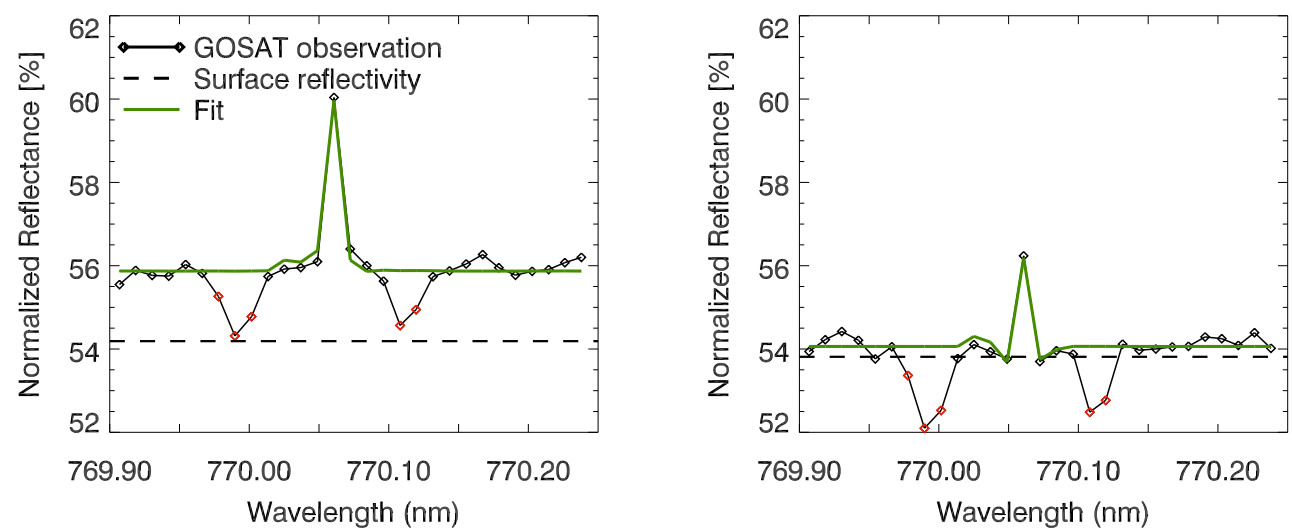

Fig. 5. Normalized reflectance (Earth radiance normalized by the solar spectra in the GOSAT P polarization, black and red diamonds; red are not used in spectral fit), spectral fit (green solid line), and derived reflectivity (black dashed line) in the vicinity of the K I Fraunhofer line showing contrast between active vegetation over the Eastern United States (left) and the Sahara (right) on 2 and 1 July 2009 , respectively.

depend upon the absolute radiance error. The derived spectral residual term is implicity included in the Jacobian.

For $E^{*}$, we use several GOSAT solar spectra taken closest in time to Earth radiance observations (within a few hours) averaged together to produce a composite spectrum. Before the spectral fit, we first perform a rough adjustment to spectrally align the solar and Earth spectra. We added a wavelength shift term to the fit to further improve the alignment. This term can make the minimization non-linear. However, we found that by providing an initial shift, the problem was sufficiently linear that multiple iterations were not necessary.

Here, we assume a constant wavelength dependence of $F$ and $R$ (or $K$ or $K^{\prime}$ ) over this band. This assumption could be relaxed as would be appropriate for a larger spectral fitting window as discussed by e.g., Meroni et al. (2010). We could also account for atmospheric scattering and absorption using a radiative transfer code, though we have not done so here. Note that an error in absolute calibration of $I(\lambda)$ will be present in the retrieved $F$.

Our initial results showed positive values of fluorescence over the Sahara where none was expected. The root cause was found to be unexplained systematic spectral structure in the core of the K I line that we believe is due in part to undersampling and the effects of rotational-Raman scattering.

To account for these affects, we derived averaged spectral signatures from pixels where we expect zero fluorescence. Here we used clear-sky pixels from several days over the Sahara. We derived these residuals separately for several binned values of the derived spectral shifts between Earth and solar spectra. We found that the overall spectral shapes were similar for the various shift values, but differed somewhat in the details. We then incorporate the derived residuals for the appropriate value of the wavelength shift into our spectral fit. Note that this approach does not account for the $\theta$ dependence of the RRS filling-in. This will result in an overestimate of fluorescence filling-in at high $\theta$ as the RRS filling-in will not be completely accounted for at these large solar zenith angles.

Samples of the overall fits to normalized reflectance spectra in the P polarization are shown in Fig. 5 for single pixels over active vegetation in the Eastern United States (left) and Sahara (right). Examples of the applied residuals for reflectance spectra are shown in Fig. 6. The fitted filling-in structure due to fluorescence $(F / K E(\lambda)$ in $\%)$ is also shown in Fig. 6 along with the observed minus fitted radiances (in \%). For the wavelengths used in the fits, the standard deviation of the fit is generally within about $\pm 0.3 \%$ at the continuum wavelengths, consistent with the expected GOSAT SNR. Residuals are slightly higher $(\sim 1 \%)$ in the core of the $\mathrm{K}$ line where there is higher sensitivity to undersampling and wavelength errors.

\section{Further GOSAT data processing for $F$ retrievals}

We first removed cloudy data by two different methods. The remaining data were averaged in 2 degree latitude $\times 2$ degree longitude grid boxes. In the first cloud filtering method, the concept of the cloud radiance fraction (CRF) is used. CRF is defined as the fraction of pixel radiance coming from clouds. The CRF is a useful quantity for cloudy pixel screening because there can be situations of high cloud fractions with nearly transparent clouds that would minimally affect our retrievals, while there could also be cases of low cloud fractions but extremely bright clouds that we would not want to include in our sample. Here, we used CRF derived at $450 \mathrm{~nm}$ with the Ozone Monitoring Instrument (OMI) (Levelt et al., 2006) that flies on the Aura spacecraft. The CRF is supplied in the standard $\mathrm{NO}_{2}$ data product (Bucsela et al., 2006). OMI observations are made over the same geographical area within $\sim<2 \mathrm{~h}$ of GOSAT. We used only pixels with a cloud radiance fraction $<10 \%$. 

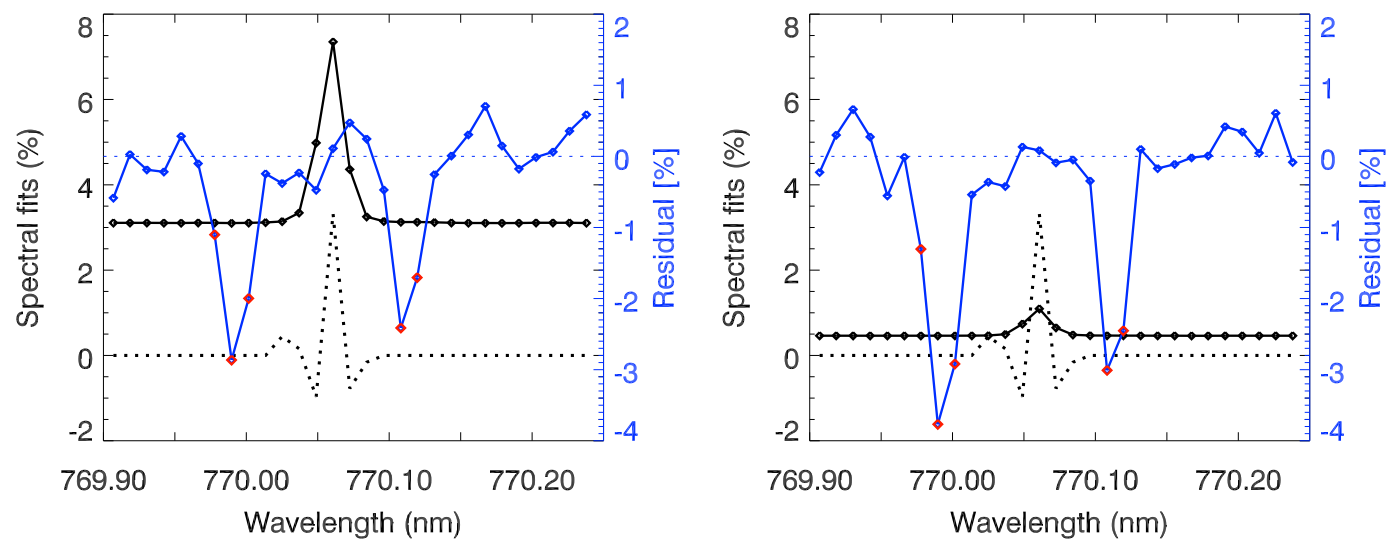

Fig. 6. Spectral structure as a percent of the continuum reflectance (left axis): dotted line is unexplained spectral structure (assumed due to undersampling and rotational-Raman scattering) and black solid line and diamonds represent the spectral fit of the fluorescence. The radiance residuals (observed minus computed) are shown by the blue solid line, where blue diamonds are for fitted wavelengths and red are for those not fitted. These are the same two pixels shown in Fig. 5 (Eastern US on left and Sahara on right). Results are for the P polarization.

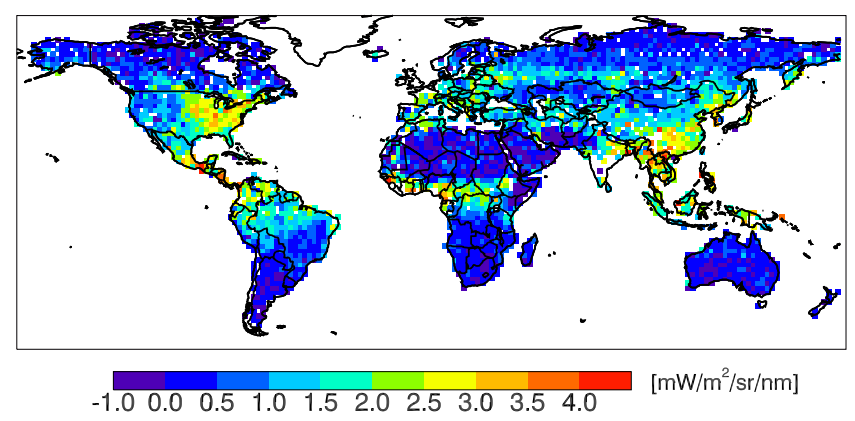

Fig. 7. Derived monthly averages for instantaneous fluorescence $F$ $\left(\mathrm{mW} \mathrm{m} \mathrm{m}^{-2} \mathrm{sr}^{-1} \mathrm{~nm}^{-1}\right)$ for July 2009 from GOSAT P polarization.

In the second cloud filtering method, we used the cloud fraction from the GOSAT CAI. Here, we removed pixels with estimated cloud fractions $>10 \%$. This provided results similar to those with the CRF. All results shown here use the second method.

We also examined radiance residuals in order to quality control the retrievals. We tested several different thresholds on the residuals including a checks on the maximum residual and mean (over wavelength) residual. We found that some pixels exhibited more noise than others. However, removing pixels with higher-than-average noise did not significantly alter the results and in some cases significantly decreased the number of samples per gridbox, leaving many gridboxes with no samples. Therefore, in the results shown below, we did not remove any pixels based on high radiance residuals though we did remove a few obviously bad pixels based on a simple threshold test.

The number of pixels averaged for a particular gridbox in a month varied from 1 to 39, with most grid boxes having between 2 and 12 observations. In dry areas with less clouds,

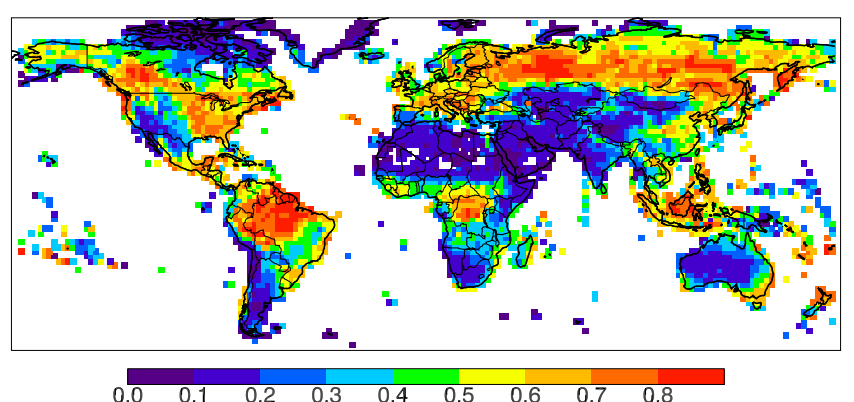

Fig. 8. MODIS FPAR product (unitless) for 20-27 July 2009.

like northern Africa, Saudi Arabia and central Australia, the number of observations ranges from about 16-28 on average.

Figure 7 shows the retrieved monthly mean $F$ for July 2009 in the same units as the Earth radiance from the P polarization. Another useful quantity that can be derived is the normalized instantaneous fluorescence yield, $\Phi$, given by

$\Phi=F_{\mathrm{f}} / \mathrm{APAR}=F_{\mathrm{f}} /(\mathrm{FPAR} \cdot \mathrm{PAR})$,

(e.g., Louis et al., 2005), where $F_{\mathrm{f}}$ is the fluorescence flux (differs with $F$ by a factor of $\pi$ if isotropic), FPAR is the fraction of radiation intercepted by the canopy, and PAR is the instantaneous (clear sky) broadband photosynthetically active radiation $(400-700 \mathrm{~nm})$.

Here, we use FPAR derived from the MODerate-resolution Imaging Spectroradiometer (MODIS) (Myneni et al., 2002) as shown in Fig. 8. We estimated clean-sky PAR (no clouds or aerosol) using the radiative transfer code of $\mathrm{Fu}$ and Liou (1992) and monthly mean total column ozone from OMI with ozone profile information from the GEOS-5 Data Assimilation System (Rienecker et al., 2007). We also used water vapor profiles from GEOS-5. Assuming that our derived 


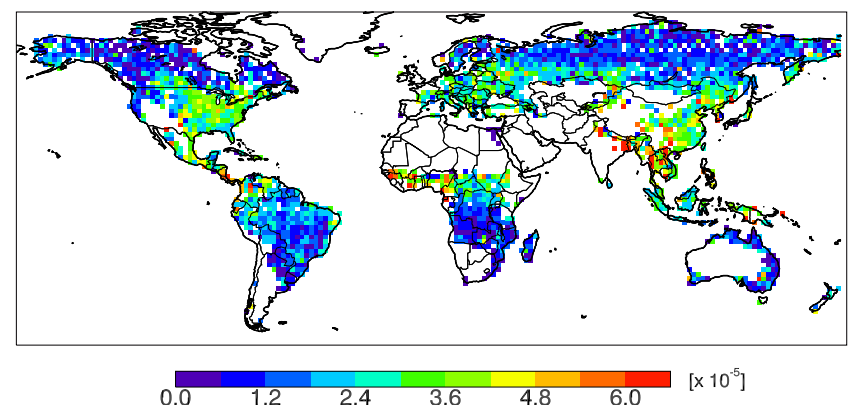

Fig. 9. Derived monthly averages for instantaneous fluorescence yield, $\Phi$, (unitless) for July 2009 from the GOSAT P polarization.
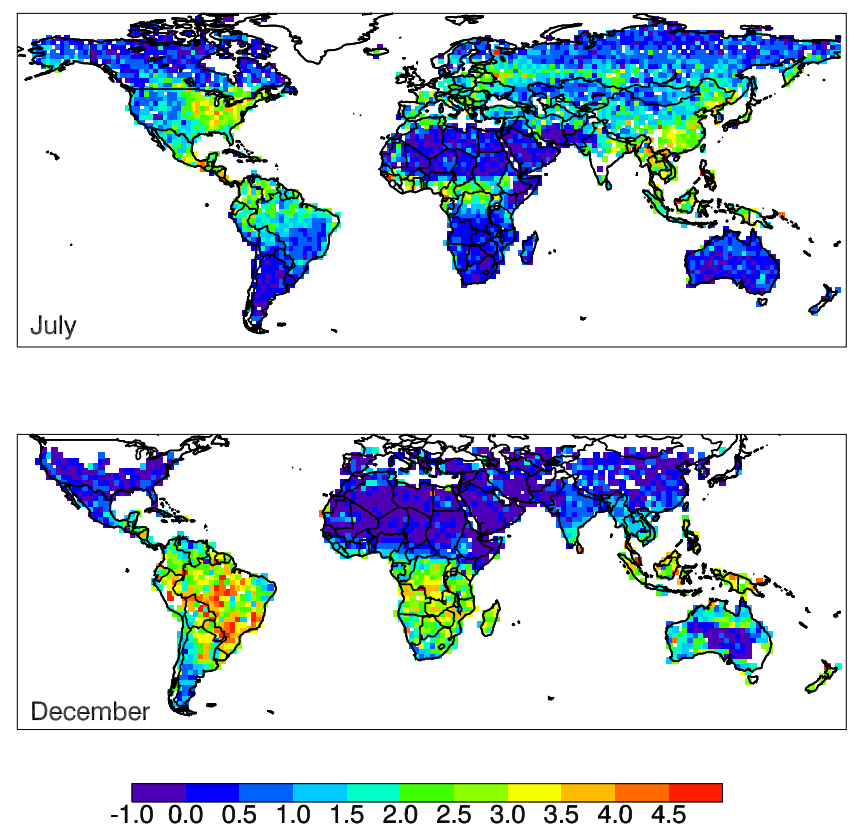

Fig. 10. Derived monthly averages for scaled fluorescence (unitless) from GOSAT for July and December 2009 for the P polarization.

fluorescence signal is isotropic, which is the traditional expectation, we may now estimate $\Phi$ for the narrow wavelength band $(\sim 1 \mathrm{~nm})$ considered here such that $\Phi$ is unitless. Figure 9 shows $\Phi(770 \mathrm{~nm})$ for July 2009. As FPAR becomes small, any errors in the $F$, FPAR, or PAR become amplified. Therefore, we only show $\Phi$ for FPAR $>0.3$.

Most subsequent results will be shown as $F$ divided by $\cos (\theta)$, a proxy for PAR. We will refer to this as "scaled fluorescence". The scaling accounts for the solar zenith angle dependence of the incoming solar irradiance, but does not account for spatial or temporal variations in FPAR, such as those related to the leaf area seen by the satellite sensor.
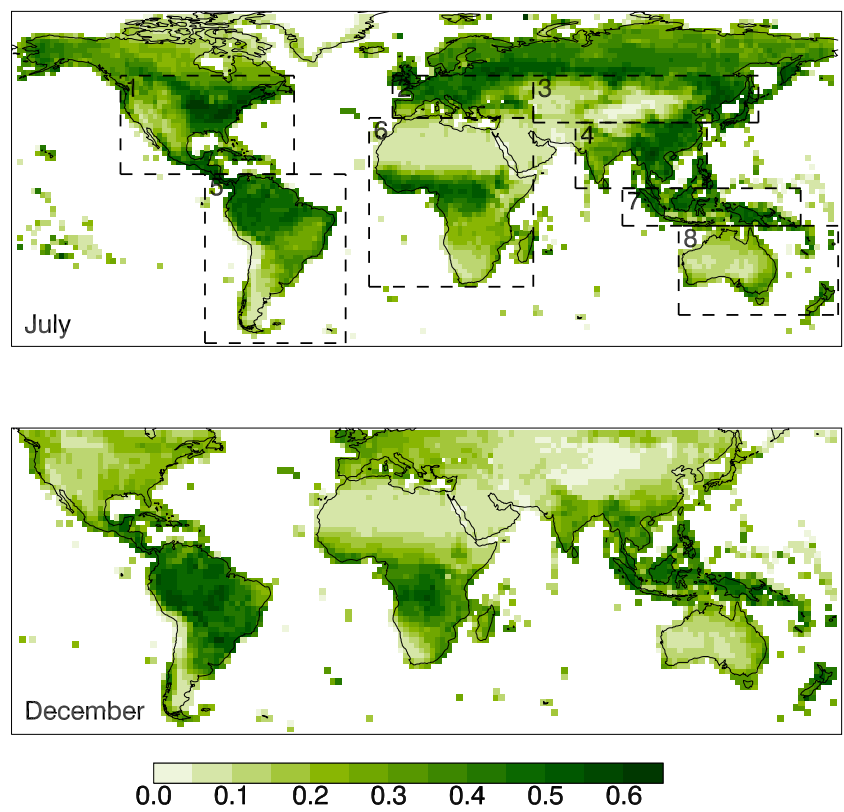

Fig. 11. Enhanced Vegetation Index (EVI) (unitless) from Aqua MODIS for July and December 2009. Boxes in top panel indicate regions of interest that will be further explored in Figs. 14-15.

\section{Results}

Figure 10 shows monthly mean scaled $F$ for July and December 2009 as retrieved from the K I solar line. The expected seasonal variation is definitively shown, namely, higher Northern Hemisphere terrestrial activity in July versus higher activity in the Southern Hemisphere in December.

We also show the analogous data for the Enhanced Vegetation Index (EVI) (Huete et al., 2002), a widely used reflectance-based vegetation index, to indicate relative greenness and to infer photosynthetic function, that was obtained over the same time periods from NASA's Aqua MODIS sensor (Fig. 11). The Aqua satellite has an ascending node equator crossing near 13:30 LT, similar to that of GOSAT. EVI data are provided as monthly mean values at $0.05^{\circ}$ spatial resolution. We have averaged the data to be compatible with our coarser grid. We found that the standard deviations in EVI for our large grid boxes were fairly high, between about 0.05 and 0.15 , for the majority of the vegetated gridboxes. This indicates that there is much spatial heteorogeneity in green biomass content within the large grid boxes. Although there are similarities between the scaled $F$ and EVI values owing to the dependence of both on the amount of green biomass seen by the sensors, some obvious differences are also evident.

Figures 12 and 13 show the full seasonal cycle in scaled $F$ for the $\mathrm{P}$ and $\mathrm{S}$ polarizations, respectively, as well as EVI and the normalized difference vegetation index (NDVI) (Tucker, 1979) for a few selected regions. Both standard 

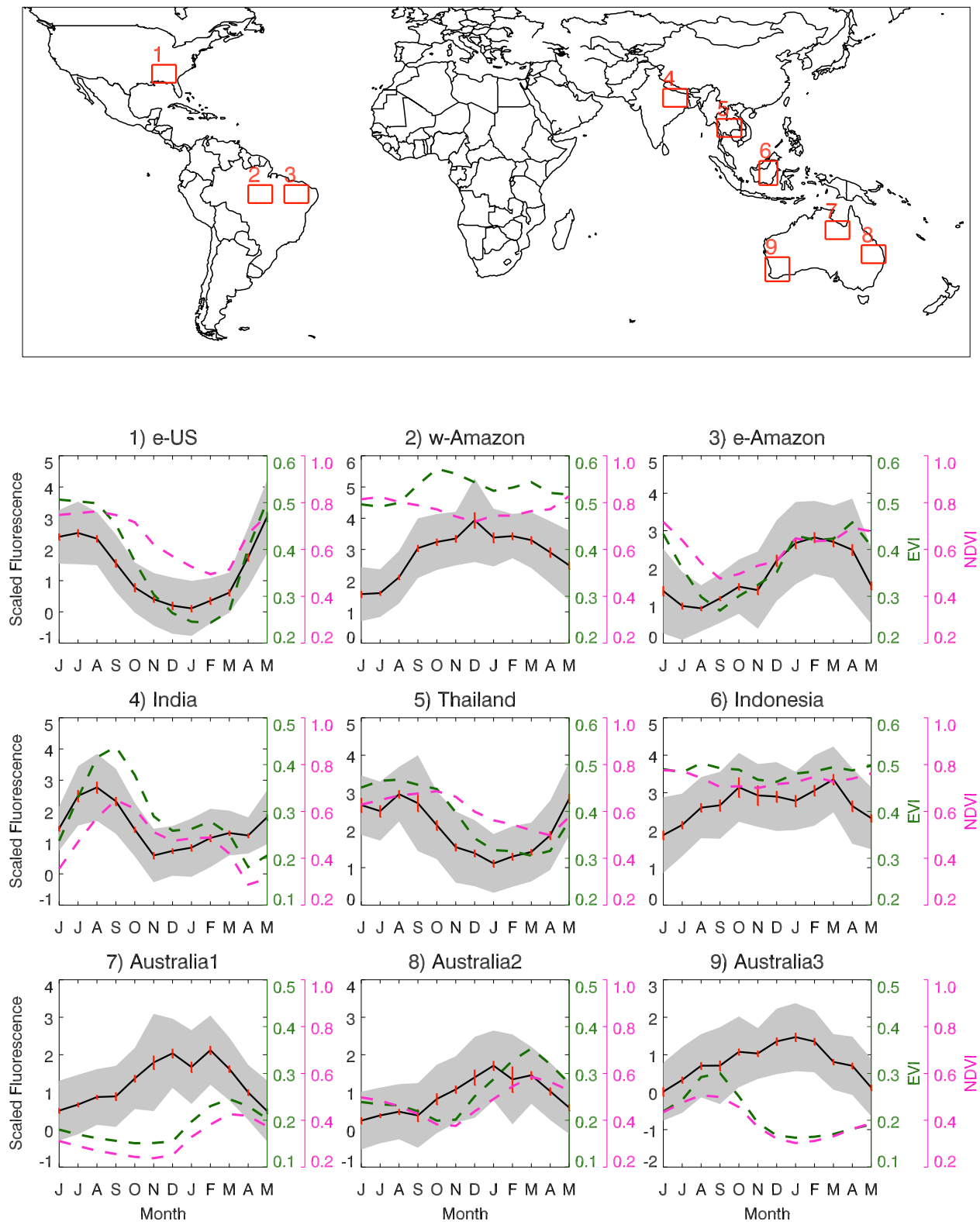

Fig. 12. Bottom panel: full seasonal cycle in scaled $F$ from the $P$ polarization for June 2009-May 2010 (left axis, unitless) for the regions indicated in the top panel; black line: monthly means; red line: errors of the mean; Shaded gray: standard deviation; dashed green (pink) line: MODIS EVI(NDVI) (right axes, unitless).

deviations and error of the mean are shown for the monthly mean $F$. Variability that contributes to the standard deviations includes that from retrieval error, the diversity of cover types included within the regions, and natural daily variability.

It should also be noted that the sampling is different for GOSAT and the MODIS EVI. Since the MODIS native spatial resolution is $1 \mathrm{~km}$ or better, there is a higher chance of seeing in between clouds. Different cloud screening techniques also contribute to sampling differences.
We use standard error propagation to compute the retrieval error covariance, $\mathbf{S}_{r}$, i.e.,

$\mathbf{S}_{r}=\left(\mathbf{H}^{T} \mathbf{S}_{\mathbf{0}}{ }^{-1} \mathbf{H}\right)^{-1}$.

Using our assumption of a diagonal error covariance with all wavelengths weighted equally (removed wavelengths affected by absorption not included), Eq. (6) simplifies to

$\mathbf{S}_{r}=\sigma^{2}\left(\mathbf{H}^{T} \mathbf{H}\right)^{-1}$, 

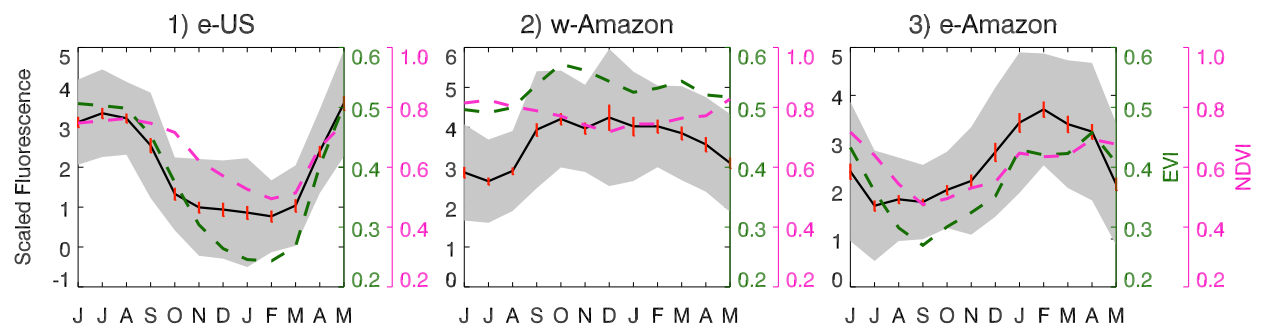

6) Indonesia

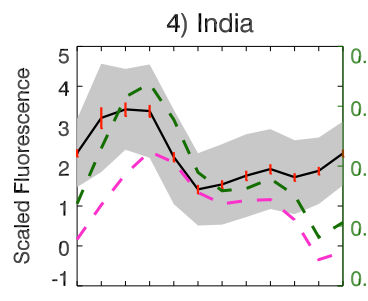

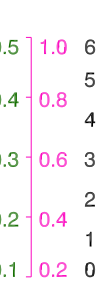

J JASOND J FMAM

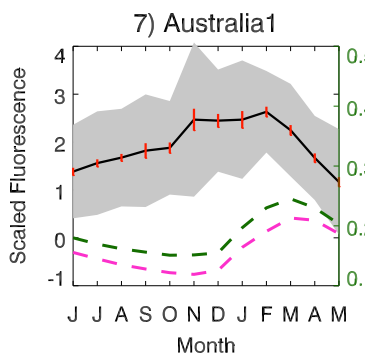

5) Thailand

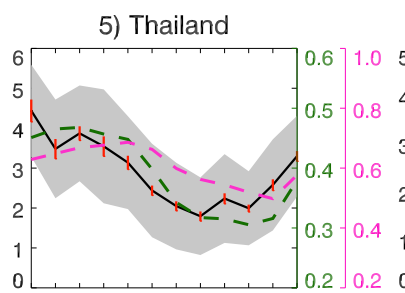

J JASOND JFMAM

8) Australia2

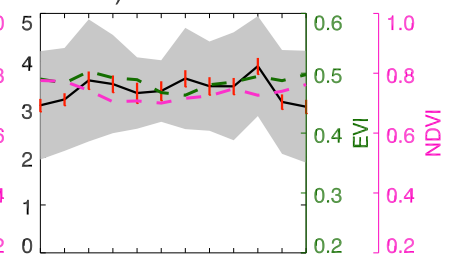

J JASOND J F M A M

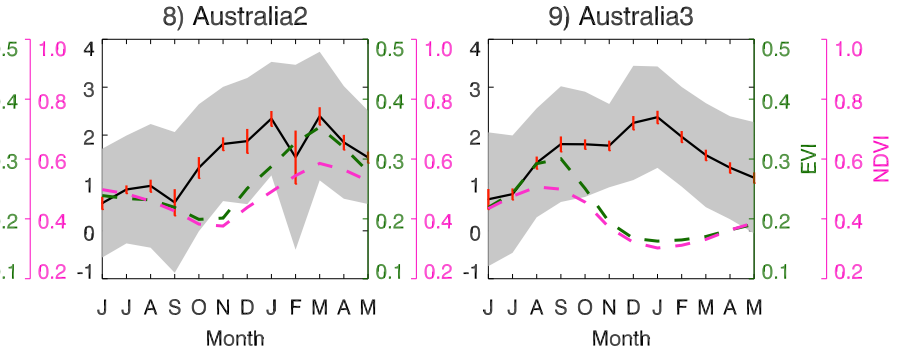

Fig. 13. Similar to bottom panel of Fig. 12 but derived from the GOSAT S polarization data.

where $\sigma$ is the radiance error standard deviation that we assume here is approximated by $I / \mathrm{SNR}$. With this assumption (note that this is not a good assumption for all types of instrumentation), the error standard deviation in $F$ is proportional to $\sigma$ and thus proportional to $\cos (\theta) \cdot R / \mathrm{SNR}$. The expected error in scaled $F$ is then proportional to the $R / \mathrm{SNR}$, and the error in terms of $\%$ of the continuum radiance goes as 1/SNR. For our spectral window, we find that the precision of scaled $F$ ranges from approximately 0.18 for $\mathrm{SNR}=300$ and $R=0.2$ to 1.33 for $R=0.5$ and $\mathrm{SNR}=100$ for a single measurement in one polarization. For our GOSAT fitting window, the error in terms of $\%$ of the continuum is approximately $0.453 \%(1.35 \%)$ for SNR of 300(100) for unpolarized measurements.

The actual scaled $F$ retrieval standard deviations, that encompass both retrieval error and natural variability, are generally between about 0.6 and 1.2 for moderate values of reflectivity (up to 0.5 ) and higher over the very bright Sahara (between about 1.2 and 2.0). The Sahara results are more consistent with a lower SNR close to 100, similar to our computed spectral residuals in the core of the $\mathrm{K}$ line.

As expected, over the Eastern US, a clear increase in scaled $F$ is seen during the spring months (April and May) with a peak in early summer (June/July). This seasonal cycle is also seen in the EVI that has a slightly greater seasonal contrast (maximum vs. minimum) than scaled $F$.
We next examine two Amazonia regions, one near the East coast of Brazil and one more towards the west in the central Amazon rainforest region (Figs. 12-13, panels 2-3). In the westernmost Amazon pixel (panel 2), the dry season (JulyNovember) green up reported by Huete et al. (2006) for 2005 is seen here between September 2009 and January 2010 in both scaled $F$ and EVI, with scaled $F$ leading by approximately one month beginning in August. In this region, trees with deep roots may have more continuous access to deep soil moisture (e.g., Nepstad et al., 1994). Here, EVI follows PAR which depends primarily on cloud cover and peaks during the dry season (Huete et al., 2006). However, this temporal pattern is not captured in the NDVI; NDVI values peak in June/July for this region and decline to a minimum in December. In the other regions shown here, the NDVI is qualitatively similar (in the seasonal cycle) to the EVI.

In the eastern Amazon area (Figs. 12-13, panel 3), a different pattern is seen with a brown-down in the early part of the dry season in EVI, NDVI, and scaled $F$, consistent with analysis over grassland pasture sites in previous years by Huete et al. (2006). In this region, forest conversion has occurred where deep-rooted trees have been replaced with shallow-rooted vegetation that responds more to soil moisture stress. The steepest decline in scaled $F$ occurs from April to May, while a sharp decline in EVI is seen from June through September. The scaled $F$ shows an increase starting in September, while the EVI increase begins in October. 


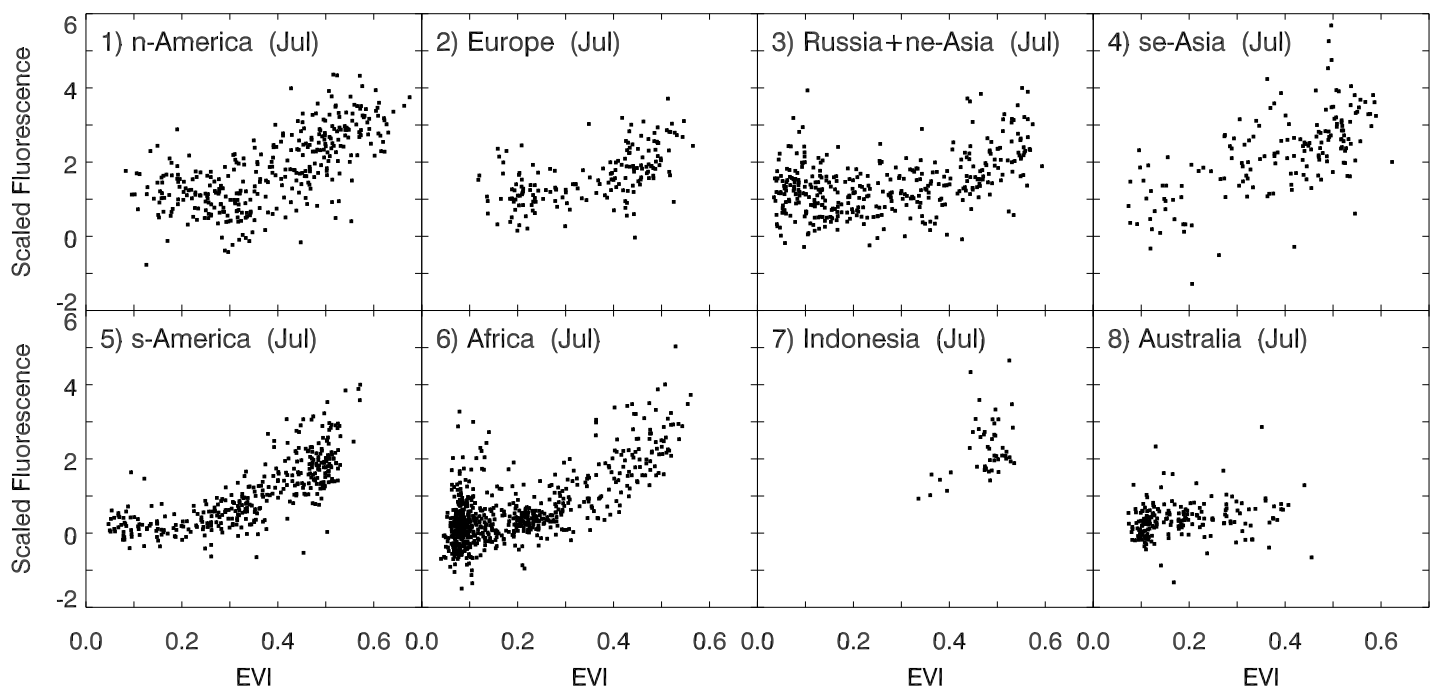

Fig. 14. Scatter plots of the GOSAT scaled $F$ from the P polarization versus the MODIS enhanced vegetation index (EVI) (both unitless) for July 2009 for different regions shown in Fig. 11. Each point represents a monthly mean from a single $2^{\circ} \times 2^{\circ}$ grid box.

Over Indonesia (Figs. 12-13, panel 6), there is little seasonal change in EVI (and NDVI), although scaled $F$ shows a significant minimum in June during the dry season when biomass burning typically takes place. El Niño began around this time in 2009 leading to a drier than normal season; widespread haze due to fires was observed in the region from June through September. Logging and forest conversion have occurred here, resulting in more vegetation stress during the dry season, especially during dry years associated with El Niño.

In the north of Australia (Figs. 12-13, panel 7), EVI (and NDVI) generally peaks in the austral autumn owing to the summer monsoonal rains. In contrast, we see a more broad peak in $F$ starting earlier. Higher spatial scale studies show significant variability in NDVI in this region as well as interannual variability (e.g. Martin et al., 2009). A different pattern is seen in the EVI in the south western region of Australia with a distinct peak in the spring (Fig. 12, panel 9). This pattern is not seen in the derived fluorescence. These regions warrant further study and investigation into potential effects of sub-pixel variability and sources of error in the satellite-derived products.

Similar seasonal cycles are obtained in $\mathrm{P}$ and $\mathrm{S}$ polarizations. Our simulations show that in clear skies, the degree of linear polarization should be relatively small $(<10 \%)$ for surface reflectivities $>0.1$ up to solar zenith angles of $70^{\circ}$. Slightly higher values of scaled $F$ are obtained in the S polarization that has higher throughput in band 1 . The standard deviations are also higher in the $\mathrm{S}$ polarization. As the temporal and spatial patterns for $\mathrm{P}$ and $\mathrm{S}$ polarizations are very similar, all subsequent results will be shown only for the $\mathrm{P}$ polarization. Note that small differences in the filling-in of the $\mathrm{K} I$ line for $\mathrm{P}$ and $\mathrm{S}$ polarizations can be caused by differences in rotational Raman scattering filling-in that will have different dependences on solar zenith angle.

We next compare and contrast the monthly gridbox averages for the derived and scaled $F$ with those for EVI, for the eight geographic regions outlined in Fig. 11. The scaling of $F$ accounts for variations in $F$ related to incoming PAR while the vegetation indices can serve as a proxy for FPAR. Details are seen in the scatter diagrams of Figs. 14-15.

All of these plots show a large amount of scatter in the relationship between scaled $F$ and EVI. This scatter results from retrieval error both in the EVI and scaled $F$, spatial and temporal sampling differences in the two derived quantities arising in part from sub-gridbox heteorgeneity, and natural variability between the two quantities. As shown in Fig. 12, the standard deviation in scaled $F$ for a relatively small region is about 1 unit. The error of the mean then depends upon the number of observations for a given gridbox. Over most moderately to heavily vegetated areas, the monthly-averaged $F$ error of the mean is less than about 0.3 for most pixels with a small fraction having errors up to 0.5 . The scatter can also be attributed to the fact that scaled $F$ emcompasses a relationship with instantaneous photosynthesis that may be complex rather than a more straight-forward relationship with potential photosynthesis represented by the vegetation indices.

These continental or large regional blocks obviously include a variety of vegetation types such as forests, grasslands, and croplands that have different $F$ and EVI values. Even though the plots show significant scatter, for most regions there is an evident positive but non-linear relationship between $\mathrm{F}$ and EVI, but with a great deal of scatter. 


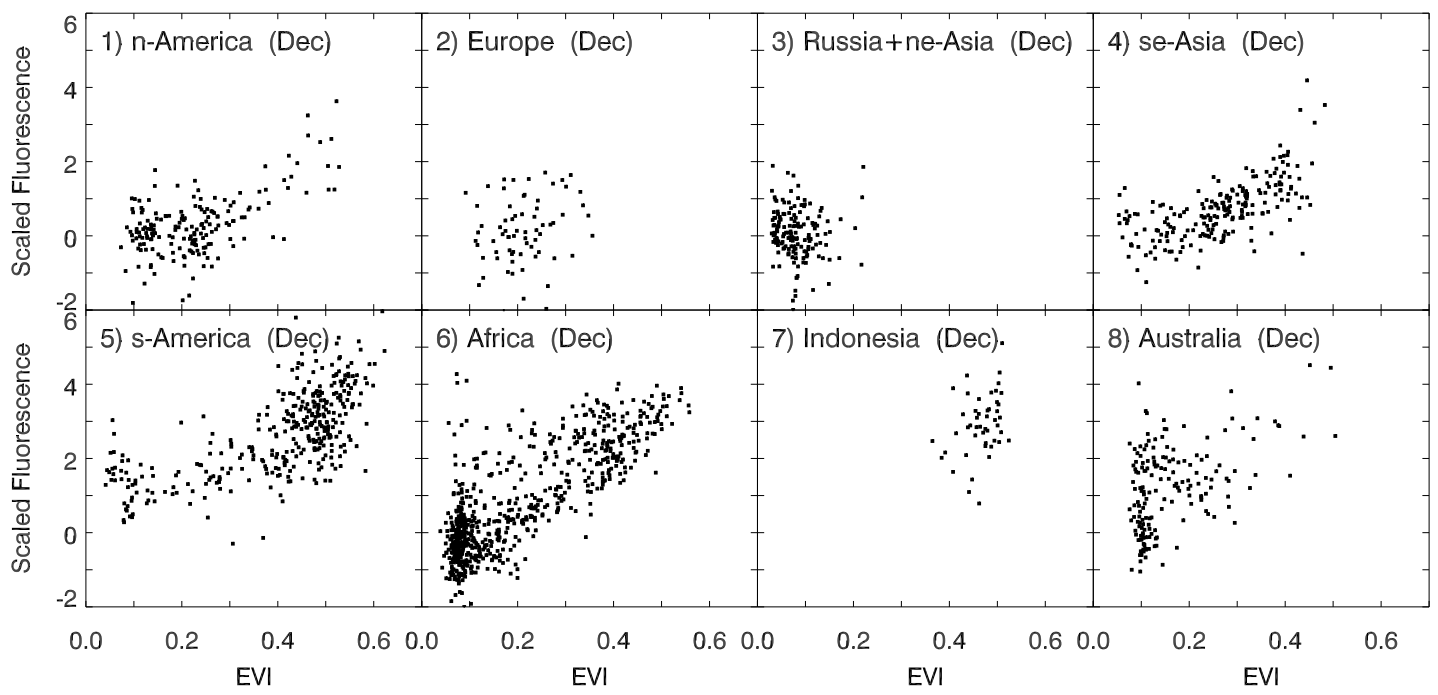

Fig. 15. Similar to Fig. 14 but showing scaled $F$ from the P polarization versus the MODIS enhanced vegetation index (EVI) (both unitless) for December 2009.

This relationship is similar in shape and intensity value ranges in July in the Northern Hemisphere (Fig. 14, panels 1, $2,3,4)$. In contrast, these same North American regions exhibit very low $F(<\sim 1)$ across a range of EVI values (up to $\sim 0.4$ ) in December (Fig. 15). The points with EVI near 0.4 may indicate low photosynthetic activity by standing green vegetation (e.g., coniferous forests) as has been suggested by e.g. Soukupová et al. (2008). Another example where moderate EVI values (0.2-0.4) imply the presence of green vegetation but where the fluorescence is at or near the detection threshold is shown in the July South America panel (Fig. 14, panel 5). This may indicate that the vegetation has retained greenness but is not physiologically active during the dry winter season.

Africa shows a clear positive and linear relationship for $F$ :EVI across the observed greater range of $F$ and EVI values in both July and December (Figs. 14 and 15.) This occurs because Africa spans both the Northern and Southern Hemispheres and has a large number of vegetation types, including the extremes of tropical forests and the Sahara desert. Indonesia, a tropical low latitude region, shows no correlation between EVI and fluorescence and has the same $F$ :EVI cluster in both the July and December seasons.

Southern Hemisphere regions (Fig. 15) during the growing season (December) exhibit highly variable $F$ versus EVI, with no clear relationships demonstrated here. South America and Australia show very low $F$ in July (winter) over most of the EVI range $(<0.4)$. Australia has mostly low to moderate EVI values during these months that show no correlation with fluorescence. The maps in Fig. 10 indicate that active fluorescence occurs over Australia primarily along the continental edges in the austral spring/early summer, a pattern not expressed distinctly in the corresponding EVI map.

\section{Conclusions and ongoing work}

We have demonstrated here for the first time that fluorescence from vegetation can be measured globally from space. While satellite-derived vegetation indices such as the EVI provide estimates of the potential (or maximum) photosynthesis, the fluorescence retrievals shown here may reflect a regional-scale measure of actual (as compared with inferred potential) instantaneous and dynamic photosynthetic activity derived by measuring light emission that originates from the cores of the photosynthetic machinery. Our results suggest that retrieved fluorescence provides information that is independent of EVI and could be used to augment important global productivity seasonal dynamics information.

We have demonstrated that space-based missions that were specifically designed to measure $\mathrm{CO}_{2}$ concentrations can also be used to measure an important value-added carbon product: regional-scale chlorophyll fluorescence. Further development of this product and studies using this data will help to maximize the benefits of space-based carbon missions such as GOSAT and a reflight of the NASA Orbiting Carbon Observatory (OCO) (Crisp, 2004).

The FLuorescence EXplorer (FLEX) mission (Rascher, 2007; European Space Agency, 2008) was selected in 2006 for assessment as the result of the European Space Agency's call for core Earth Explorer Mission ideas and has been since reproposed. Our study provides evidence that such a mission could provide important information on photosynthetic efficiency of terrestrial ecosystems at a global scale. This information combined with data from other satellites will help to better quantify relationships between the carbon and water cycles and their coupling with the Earth's climate. The FLEX missions plans to utilize the $\mathrm{O}_{2}-\mathrm{A}$ band for chlorophyll 
fluorescence retrievals (Guanter et al., 2010), whereas OCO2 could use the solar Fraunhofer $\mathrm{K}$ line or other nearby lines; its spectral coverage is similar to GOSAT's, while it has slightly lower spectral resolution but higher SNR (Frankenberg et al., 2011) and a smaller ground footprint.

A chlorophyll fluorescence product may also be feasible from Geostationary (GEO) orbit using instrumentation being proposed for the NASA decadal survey GEO-Coastal and Air Pollution Events (GEO-CAPE) mission. This would provide important information regarding the links between pollutants, such as tropospheric $\mathrm{O}_{3}$ that can damage vegetation, and climate, through the uptake of $\mathrm{CO}_{2}$, the primary anthropogenic greenhouse gas.

As most previous studies of $F$ have been conducted at the leaf scale and at near-surface, care must be taken to properly interpret this large pixel data. The influence of canopy structure needs to be investigated in order to fully understand its influence on retrieved fluorescence and consequently derived relationships with key carbon-related parameters such as gross primary production (GPP) and light-use efficiency (LUE) (Damm et al., 2010).

We have not taken into account the directionality of the emitted fluorescence, although this is a reasonable approach since $F$ has traditionally been assumed to be isotropic. There may also be errors in absolute calibration of the Earth radiance data as well as errors associated with our spectral fitting including the neglect of rotational-Raman scattering. Therefore, our reported absolute values must be interpreted with caution. The association of $F$ with biomes, rather than whole continents or arbitary large regions, will improve the understanding of this signal.

Clearly, future research will need to include developing appropriate validation strategies for these products. Comparisons with point measurements such as net $\mathrm{CO}_{2}$ uptake from flux towers present challenges as these measurements may not be representative of the much larger satellite footprints. However, comparisons of temporal variations may be useful. A longer time series of satellite-derived fluorescence will be helpful in conducting such comparisons. In addition, studies are needed to develop a better understanding of the physical linkages between $F$ and other geophysical and observed (both by remote sensing and in situ) parameters. For example, recent studies have focused on the relationship between satellite-derived scaled Photochemical Reflectance Index (PRI) and light use efficiency (LUE) obtained from an eddy covariance flux tower (e.g., Drolet et al., 2005). We are currently processing more GOSAT data in an effort to map global complete seasonal cycles and to quantify interannual variations in fluorescence owing to events such as extreme drought.

We also plan to improve our retrieval by accounting for instrumental effects such as polarization sensitivity and wavelength calibration as described in Yoshida et al. (2010). A new version of GOSAT level 1B data with improved calibration in band 1 is expected to be released in the near future
(A. Kuze, personal communication, 2011), and we will examine whether these improvements affect our $F$ retrievals.

Accounting for chlorophyll fluorescence in the $\mathrm{K} I$ line could assist in the interpretations made for $F$ in the $\mathrm{O}_{2}-\mathrm{A}$ band. Furthermore, this should also help to improve the retrieval of $\mathrm{CO}_{2}$, as well as aerosol and cloud information from the $\mathrm{O}_{2}$-A band. This band was designed to be an integral part of both the GOSAT and NASA OCO missions (e.g., Kuang et al., 2002; Crisp, 2004; Frankenberg et al., 2011). It has been used with the SCanning Imaging Absorption SpectroMeter for Atmospheric CHartographY (SCIAMACHY) to obtain an accurate description of the solar light path over both clear and cloudy pixels (Reuter et al., 2010) to aid in $\mathrm{CO}_{2}$ retrievals. Without proper accounting for the variability of the fluorescence signal, the accuracy of $\mathrm{CO}_{2}$, cloud, and aerosol information from these sensors will be degraded.

Acknowledgements. The authors thank C. Frankenberg and two anonymous reviewers for helpful comments that helped to improve the paper. We also wish to thank the GOSAT project and the MODIS data processing team for making available the data sets used here. We also thank A. Kuze for providing helpful information on the GOSAT instrument, and W. Cook, K. F. Huemmrich, J. Mao, C. Weaver, and A. da Silva for simulating ideas and helpful discussions.

Edited by: T. Laurila

\section{References}

Bucsela, E. J., Celarier, E. A., Wenig, M. O., Gleason, J. F., Veefkind, J. P., Boersma, K. F., and Brinksma, E. J.: Algorithm for $\mathrm{NO}_{2}$ vertical column retrieval from the Ozone Monitoring Instrument, IEEE T. Geosci. Remote, 44, 1245-1258, 2006.

Campbell, E., Middleton, E. M., Corp, L. A., and Kim, M. S.: Contribution of chlorophyll fluorescence to the apparent vegetation reflectance, Sci. Total Environ., 404, 433-439, 2008.

Chance, K. and Kurucz, R. L.: An improved high-resolution solar reference spectrum for Earth's atmosphere measurements in the ultraviolet, visible, and near infrared, J. Quant. Spectrosc. Ra., 111, 1289-1295, 2010.

Chance, K., Kurosu, T. P., and Sioris, C. E.: Undersampling correction for array detector-based satellite spectrometers, Appl. Optics, 44, 1296-1304, 2005.

Corp, L. A., McMurtrey, J. E., Middleton, E. M., Mulchi, C. L., Chappelle, E. W., and Daughtry, C. S. T.: Fluorescence Sensing Systems: In vivo detection of biophysical variations in field corn due to nitrogen supply, Remote Sens. Environ., 86, 470479, 2003.

Corp, L. A., Middleton, E. M., McMurtrey, J. E., Campbell, P. K. E., and Butcher, L. M.: Fluorescence sensing techniques for vegetation assessment, Appl. Optics, 45, 1023-1033, 2006.

Crisp, D.: The Orbiting Carbon Observatory (OCO) mission, Adv. Space Res., 34, 700-709, 2004.

Damm, A., Elbers, J., Erler, A., Giolis, B., Hamdi, K., Hutjes, R. W. A., Kosvancova, M., Meroni, M., Migliettas, F., Moersch, A., Moreno, J., Schickling, A., Sonnenschein, R., Udelhoven, T., 
Linden, S., Van Der Hostert, P., and Rascher, U.: Remote sensing of sun-induced fluorescence to improve modeling of diurnal courses of gross primary production (GPP), Glob. Change Biol., 16, 171-186, doi:10.1111/j.1365-2486.2009.01908.x, 2010.

Davidson, M., Berger, M., Moya, I., Moreno, J., Laurila, T., Stoll, M.-P., and Miller, J.: Mapping photosynthesis from space - a new vegetation-fluorescence technique, ESA Bull., 116, 34-37, 2003.

Drolet, G. G., Huemmrich, K. F., Hall, F. G., Middleton, E. M., Black, T. A., Barr, A. G., and Margolis, H. A.: A MODIS-derived photochemical reflectance index to detect inter-annual variations in the photosynthetic light-use efficiency of a boreal deciduous forest, Remote Sens. Environ., 98, 212-224, 2005.

European Space Agency: ESA SP-1313/4 Candidate Earth Explorer Core Missions - Reports for Assessment: FLEX - FLuorescence EXplorer, published by ESA Communication Production Office, Noordwijk, The Netherlands, www.congrex.nl/09c01/SP1313-4_ FLEX.pdf, 2008.

Frankenberg, C., Butz, A., and Toon, G. C.: Disentangling chlorophyll fluorescence from atmospheric scattering effects in O2Aband spectra of reflected sun-light, Geophys. Res. Lett., 38, L03801, doi:10.1029/2010GL045896, 2011.

Fu, Q. and Liou, K.-N.: On the correlated k-distribution method for radiative transfer in nonhomogeneous atmospheres, J. Atmos. Sci., 49, 2139-2156, 1992.

Guanter, L., Alonso, L., Gómez-Chova, L., Amorós-López, J., VilaFrancés, J., and Moreno, J.: Estimation of solar-induced vegetation fluorescence from space measurements, Geophys. Res. Lett., 34, L08401, doi:10.1029/2007GL029289, 2007.

Guanter, L., Alonso, L., Gómez-Chova, L., Meroni, M., Preusker, R., Fischer, J., and Moreno, J.: Developments for vegetation fluorescence retrieval from spaceborne high-resolution spectrometry in the $\mathrm{O}_{2}$-A and $\mathrm{O}_{2}$-B absorption bands, J. Geophys. Res., 115, D19303, doi:10.1029/2009JD013716, 2010.

Huete, A. R., Didan, K., Miura, T., Rodriguez, E. P., Gao, X., and Ferreira, L. G.: Overview of the radiometric and biophysical performance of the MODIS vegetation indices, Remote Sens. Environ, 83, 195-213, 2002.

Huete, A. R., Didan, K., Shimabukuro, Y. E., Ratana, P., and Saleska, S. R.: Amazon rainforests green-up with sunlight in dry season, Geophys. Res. Lett., 33, L06405, doi:10.1029/2005GL025583, 2006.

Kuang, Z., Margolis, J., Toon, G., Crisp, D., and Yung, Y.: Spaceborne measurements of atmospheric $\mathrm{CO}_{2}$ by high-resolution NIR spectrometry of reflected sunlight: an introductory study, Geophys. Res. Lett., 29, 1716, doi:10.1029/2001GL014298, 2002.

Kuze, A., Suto, H., Nakajima, M., and Hamazaki, T.: Thermal and near infrared sensor for carbon observation Fourier-transform spectrometer on the Greenhouse Gases Observing Satellite for greenhouse gases monitoring, Appl. Optics, 48, 6716-6733, 2009.

Levelt, P. F., van den Oord, G. H. J., Dobber, M. R., Malkki, A., Visser, H., de Vries, J., Stammes, P., Lundell, J., and Saari, H.: The Ozone Monitoring Instrument, IEEE T. Geosci. Remote, 44, 1093-1101, 2006.

Louis, J., Ounis, A., Ducruet, J.-M., Evain, S., Laurila, T., Thum, T., Aurela, M., Wingsle, G., Alonso, L., Pedros, R., and Moya, I.: Remote sensing of sunlight-induced chlorophyll fluorescence and reflectance of Scots pine in the boreal forest during spring recovery, Remote Sens. Environ., 96, 37-48, 2005.

Maier, S. W., Günther, K. P., and Stellmes, M.: Remote sensing and modelling of solar induced fluorescence, Proc. 1st Workshop Rem. Sens. Solar Induced Vegetation Fluorescence, ESTEC, Noordwijk, The Netherlands, 19-20 June, 2002.

Maier, S. W., Günther, K. P., and Stellmes, M.: Sun-induced fluorescence: A new tool for precision farming, in: Digital imaging and spectral techniques: Applications to precision agriculture and crop physiology, edited by: VanToai, T., Major, D., McDonald, M., Schepers, J., and Tarpley, L., Madison, American Society of Agronomy, 209-222, 2003.

Martin, D., Grant, I., Jones, S., and Anderson, S.: Development of satellite vegetation indices to assess grassland curing across Australia and New Zealand, in: Innovations in Remote Sensing ad Photogrammetry, Lecture Notes in Geoinformation and Cartography, Part 3, edited by: Jones, S. and Reinke, K., Springer Berlin Heidelberg, 211-227, doi:10.1007/978-3-54093962-7_17, 2009.

Meroni, M. and Colombo, R.: Leaf level detection of solar induced chlorophyll fluorescence by means of a subnanometer resolution spectroradiometer, Remote Sens. Environ., 103, 438-448, 2006.

Meroni, M., Picchi, V., Rossini, M., Cogliati, S., Panigada, C., Nali, C., Lorenzini, G., and Colombo, R.: Leaf level early assessment of ozone injuries by passive fluorescence and photochemical reflectance index, Int. J. Remote Sens., 29, 5409-5422, 2008.

Meroni, M., Rossini, M., Guanter, L., Alonso, L., Rascher, U., Colombo, R., and Moreno, J.: Remote sensing of solar-induced chlorophyll fluorescence: Review of methods and applications, Remote Sens. Environ., 113, 2037-2051, 2009.

Meroni, M., Busetto, L., Colombo, R., Guanter, L., Moreno, J., and Verhoef, W.: Performance of spectral fitting methods for vegetation fluorescence quantification, Remote Sens. Environ., 114, 363-374, 2010.

Middleton, E. M., Corp, L. A., and Campbell, P. K. E.: Comparison of measurements and FluorMOD simulations for solar induced chlorophyll fluorescence and reflectance of a corn crop under nitrogen treatments, Int. J. Remote Sens., Special Issue for the Second International Symposium on Recent Advances in Quantitative Remote Sensing (RAQRSII), 29, 5193-5213, 2008.

Middleton, E. M., Cheng, Y.-B., Corp, L. A., Huemmrich, K. F., Campbell, P. K. E., Zhang, Q.-Y., Kustas, W. P., and Russ, A. L.: Diurnal and seasonal dynamics of canopy-level solar-induced chlorophyll fluorescence and spectral reflectance indices in a cornfield, Proc. 6th EARSeL SIG Workshop on Imaging Spectroscopy, CD-Rom, 12 pp., Tel-Aviv, Israel, 16-19 March, 2009.

Moya, I., Camenen, L., Evain, S., Goulas, Y., Cerovic, Z. G., Latouche, G., Flexas, J., and Ounis, A.: A new instrument for passive remote sensing: 1. Measurements of sunlight-induced chlorophyll fluorescence, Remote Sens. Environ., 91, 186-197, 2004.

Myneni, R. B., Hoffman, W., Knyazikhin, Y., Privette, J. L., Glassy, J., Tian, Y., Wang, Y., Song, X., Zhang, Y., Smith, G. R., Lotsch, A., Friedl, M., Morisette, J. T., Votava, P., Nemani, R. R., and Running, S. W.: Global products of vegetation leaf area and fraction absorbed PAR from year one of MODIS data, Remote Sens. Environ., 83, 214-231, 2002.

Nepstad, D. D., de Carvalho, C. R., Davidson, E. A., Jipp, P. H., Lefebvre, P. A., Negreiros, G. H., da Silva, E. D., Stone, T. A., Trumbore, S. E., and Vieira, S.: The role of deep roots in the 
hydrological and carbon cycles of Amazonian forests and pastures, Nature, 372, 666-669, 1994.

Rascher, U.: FLEX - Fluorescence Explorer: A remote sensing approach to quatify spatio-temporal variations of photosynthetic efficiency from space, Photosynth. Res., 91, 293-294, 2007.

Rascher, U., Agati, G., Alonso, L., Cecchi, G., Champagne, S., Colombo, R., Damm, A., Daumard, F., de Miguel, E., Fernandez, G., Franch, B., Franke, J., Gerbig, C., Gioli, B., Gómez, J. A., Goulas, Y., Guanter, L., Gutiérrez-de-la-Cámara, Ó., Hamdi, K., Hostert, P., Jiménez, M., Kosvancova, M., Lognoli, D., Meroni, M., Miglietta, F., Moersch, A., Moreno, J., Moya, I., Neininger, B., Okujeni, A., Ounis, A., Palombi, L., Raimondi, V., Schickling, A., Sobrino, J. A., Stellmes, M., Toci, G., Toscano, P., Udelhoven, T., van der Linden, S., and Zaldei, A.: CEFLES2: the remote sensing component to quantify photosynthetic efficiency from the leaf to the region by measuring sun-induced fluorescence in the oxygen absorption bands, Biogeosciences, 6, 11811198, doi:10.5194/bg-6-1181-2009, 2009.

Rast, M. J., Bézy, J. L., and Bruzzi, S.: The ESA Medium Resolution Imaging Spectrometer MERIS - A review of the instrument and its mission, Int. J. Remote Sens., 20, 1681-1702, 1999.

Reuter, M., Buchwitz, M., Schneising, O., Heymann, J., Bovensmann, H., and Burrows, J. P.: A method for improved SCIAMACHY $\mathrm{CO}_{2}$ retrieval in the presence of optically thin clouds, Atmos. Meas. Tech., 3, 209-232, doi:10.5194/amt-3-209-2010, 2010.

Rienecker, M. M., Suarez, M. J., Todling, R., Bacmeister, J., Takacs, L., Liu, H.-C., Gu, W., Sienkiewicz, M., Koster, R. D., Gelaro, R., Stajner, I., and Nielsen, J. E.: The GEOS-5 data assimilation system - Documentation of versions 5.0.1, 5.1.0, and 5.2.0. NASA Tech. Memo. 2007-104606, vol. 27, edited by: Suarez, M. J., 101 pp., 2007.

Rothman, L. S., Jacquemart, D., Barbe, A., Chris Benner, D., Birk, M., Brown, L. R., Carleer, M. R., Chackerian, C., Chance, K., Coudert, L. H., Dana, V., Devi, V. M., Flaud, J.-M., Gamache, R. R., Goldman, A., Hartmann, J.-M., Jucks, K. W., Maki, A. G., Mandin, J.-Y., Massie, S. T., Orphal, J., Perrin, A., Rinsland, C. P., Smith, M. A. H., Tennyson, J., Tolchenov, R. N., Toth, R. A., Vander Auwera, J., Varanasi, P., and Wagner, G.: The HITRAN 2004 molecular spectroscopic database, J. Quant. Spectrosc. Ra., 96, 139-204, 2005.
Soukupová, J., Cséfalvay, L., Urban, O., Kosvancová, M., Marek, M., Rascher, U., and Nedbal, L.: Annual variation of the steadystate chlorophyll fluorescence emission of evergreen plants in temperate zone, Funct. Plant Biol., 35, 63-76, 2008.

Spurr, R. J. D., de Haan, J., van Oss, R., and Vasilkov, A. P.: Discrete ordinate radiative transfer in a stratified medium with first order rotational Raman scattering, J. Quant. Spectrosc. Ra., 109, 404-425, 2008.

Tucker, C. J.: Red and photographic infrared linear combinations for monitoring vegetation, Remote Sens. Environ., 8, 127-150, 1979.

van der Tol, C., Verhoef, W., and Rosema, A.: A model for chlorophyll fluorescence and photosynthesis at leaf scale, Agr. Forest Meteorol., 149, 96-105, 2009.

Yokota, T., Yoshida, Y., Eguchi, N., Ota, Y., Tanaka, T., Watanabe, H., and Maksyutov, S.: Global Concentrations of $\mathrm{CO}_{2}$ and $\mathrm{CH}_{4}$ Retrieved from GOSAT: First Preliminary Results, Sci. Online Lett. Atm., 5, 160-163, 2009.

Yoshida, Y., Ota, Y., Eguchi, N., Kikuchi, N., Nobuta, K., Tran, H., Morino, I., and Yokota, T.: Retrieval algorithm for $\mathrm{CO}_{2}$ and $\mathrm{CH}_{4}$ column abundances from short-wavelength infrared spectral observations by the Greenhouse Gases Observing Satellite, Atmos. Meas. Tech. Discuss., 3, 4791-4833, doi:10.5194/amtd-3-47912010, 2010.

Zarco-Tejada, P. J., Berni, J. A. J., Suarez, L., Sepulcre-Cantó, G., Morales, F., and Miller, J. R.: Imaging chlorophyll fluorescence with an airborne narrow-band multispectral camera for vegetation stress detection, Remote Sens. Environ., 113, 1262-1275, 2009. 